\title{
MusculoskeletalDisordersand Treatment
}

ORIGINAL ARTICLE

\section{Reduction in Chronic Low Back Pain Using Intervertebral Differential Dynamics Therapy (IDDT) and Routine Physio- therapy: A Retrospective Pre-Post Study}

\section{Ezinne Ekediegwu ${ }^{1 *}$, Chike Chuka ${ }^{1}$, Ifeoma Nwosu' ${ }^{2}$, Chuwkwudi Ogbueche ${ }^{2}$, Echezona Nelson Dominic EKECHUKWU 3,4,5, Chigozie Uchenwoke ${ }^{3}$ and Adesola Odole ${ }^{6}$}

${ }^{1}$ Astella Physiotherapy Clinics, Enugu, Nigeria

${ }^{2}$ Department of Medical Rehabilitation, Faculty of Health Sciences and Technology, College of Heath Sciences, Nnamdi Azikiwe University, Anambra, Nigeria

${ }^{3}$ Department of Medical Rehabilitation, Faculty of Health Sciences and Technology, College of Medicine, University of Nigeria, Nsukka, Nigeria

${ }^{4}$ Environmental and Occupational Health Unit, Institute of Public Health, College of Medicine, University of Nigeria, Nsukka, Nigeria

${ }^{5}$ LANCET Physiotherapy, Wellness and Research Centre, Enugu, Nigeria

${ }^{6}$ Department of Physiotherapy, Faculty of Clinical Sciences, College of Medicine, University of Ibadan, Nigeria

*Corresponding author: Ezinne Chika Aileen Ekediegwu, Astella Physiotherapy Clinics, Enugu and Department of Medical Rehabilitation, Faculty of Health Scienes and Technology, College of Heath Sciences, Nnamdi Azikiwe University, Anambra, Nigeria

\begin{abstract}
Background: The plethora of treatments for Low Back Pain (LBP) has increased in recent times. Opioids, spinal injection, bed rest, skin traction and surgery have remained the common forms of treatment. However, there is less emphasis on pharmacological and surgical treatments in national clinical practice guidelines. Non-surgical Spinal Decompression (NSD) is a modern, though investigational non-surgical treatment technique for LBP. The aim of this report was to analyse the outcome of LBP using NSD technique delivered by an Intervertebral Differential Dynamics Therapy (IDDT) device amidst other conservative treatments.

Method: We conducted a retrospective pre-post study of 141 one hundred adult patients who visited a private physiotherapy clinic over a three and quarter-year period. Patients were treated for an average number of 10 sessions over a 2-month period using NSD therapy (IDDT), in addition to routine physiotherapy management for LBP intensity assessed using numerical pain rating scale. To analyse the obtained data, descriptive statistics and paired t-test were used, significance level was set at $\alpha=0.05$.
\end{abstract}

Results: One hundred and forty-one patients (81 males, 60 females) were analysed. The mean age and weight of the patients were $54.73 \pm 13.82$ years and $192.39 \pm 36.10 \mathrm{lbs}$ $(87.27 \pm 16.37 \mathrm{~kg})$ respectively. The mean starting and ending pain intensity scores were $5.03 \pm 1.86$ and $4.13 \pm 1.82$ respectively on an 11-point Numerical Pain Rating Scale (NPRS). There was a statistically significant decrease in pain intensity $(\mathrm{t}=12.301, \mathrm{p}<0.001)$.

Conclusion: Statistically significant improvement in LBP could be achieved using NSD and other traditional conservative management. Long-term follow up post NSD is needful.

\section{Keywords}

Non-surgical spinal decompression, Intervertebral differential dynamics therapy, Low back pain, Nigeria

\section{Introduction}

Back-related disabilities as well as population burden have been on the increase despite numerous treatments and health-care resources $[1,2]$. This will ine-

Citation: Ekediegwu E, Chuka C, Nwosu I, Ekechukwu N, Ogbueche C, Uchenwoke C, Odole A (2021) Reduction in Chronic Low Back Pain Using Intervertebral Differential Dynamics Therapy (IDDT) and Routine Physiotherapy: A Retrospective Pre-Post Study. J Musculoskelet Disord Treat 7:098. doi. org/10.23937/2572-3243.1510098

Accepted: May 29, 2021: Published: May 31, 2021

Copyright: (C) 2021 Ekediegwu E, et al. This is an open-access article distributed under the terms of the Creative Commons Attribution License, which permits unrestricted use, distribution, and reproduction in any medium, provided the original author and source are credited. 
vitably increase, especially the number of older adults with chronic incapacity associated with inability to work which as a result, impacts on health-care costs and the workforce of a nation [3,4]. Chronic LBP (continuous pain lasting for duration of equal to or greater than 3 months) occurs in $2 \%$ to $8 \%$ of individuals with LBP [5]. In Nigeria, there is a conflicting report on the prevalence of LBP; male predominance $(0.45: 0.36)$, female preponderance (1:1.5) and equal prevalence (1:1) [6-12].

Increasing prevalence of LBP in Africa has been associated with some major risk factors such as bad posture, prolonged sitting or standing, occupational hazard, poor knowledge of back care ergonomic, poor sitting, poor transferring and lifting techniques, obesity, pregnancy, long distance driving, duty stress, psychological stress, and heavy physical work [6-8,12-19]. Other trauma-related risk factors include fall from a height and Road Traffic Accident (RTA) $[12,19]$. Amongst these factors, poor lifting technique is the most common risk factor to LBP [8].

However, breakthroughs in health outcomes of musculoskeletal conditions such as LBP which has been achieved in most Western countries are yet to be observed in Africa owing to an increased focus on other health-related issues such as malaria, poliomyelitis, communicable diseases, malnutrition and HIV/AIDS [20]. Results of previous studies revealed that supervised and individualised exercise therapy is the most effective means of preventing LBP, reducing its recurrence and resultant disability; however, opioids and bed rest are still the common forms of treatment in Africa [21-23].
Anecdotally, other forms of treatment for LBP include Tai Chi, spinal manipulation, acupuncture, massage and yoga according to current national clinical practice guideline in developed countries [24-26]. In recent times, a Non-surgical Spinal Decompression (NSD) modality has been developed for management of LBP.

Non-surgical spinal decompression is the most recent incarnation of traction therapy which entails spinal stretching on a traction table or similar motorized device (such as the modern Intervertebral Differential Dynamics Therapy (IDDT) machine (Figure 1) with the goal of relieving neck or back pain $[23,27]$. It works with the mechanism of creating a negative intra-disc pressure to promote retraction or re-positioning of the bulging or herniated disc material and create a lower pressure in the disc for the influx of healing nutrients into the disc using intermittent motorized traction [23,27]. Indications for NSD using IDDT machine include degenerative disc disease, facet joint syndrome, disc bulge or herniation [28]. It significantly reduces disc herniation size with resultant improvements in straight leg raise, disability and pain [29-31]. However, there is dearth of studies in Africa that investigated management of LBP involving non-surgical spinal decompression [2], seeing that cultural and ethnic influences on LBP have been established [32-34].

Following the limitations of hands-on treatment techniques and the pitfalls of traditional traction, Intervertebral Differential Dynamics (IDD) was developed in the late 1990's for isolated 5 to 7 millimetres of vertebral distraction surrounding an injured cervical or lumbar disc

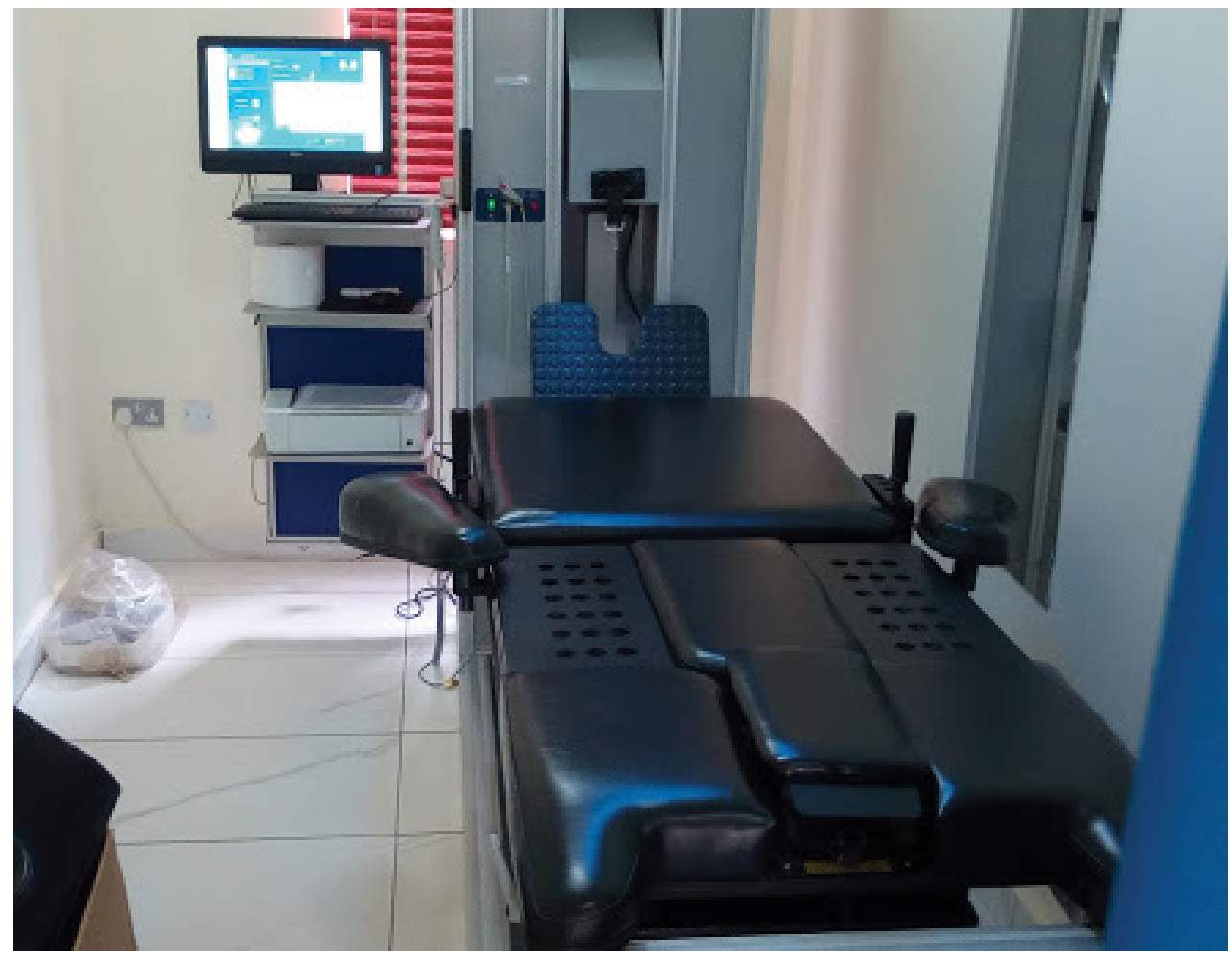

Figure 1: IDD therapy machine by Accu-Spina (Steadfast Corporation Limited, Essex, United Kingdom). 
as well as nerve [27]. It provides static, intermittent, and cycling forces on structures which causes neck or low back pain. IDD therapy comprises of different treatment sessions specifically designed for each patient lasting for 25 to 30 minutes. The negative intra-disc pressure provided by vertebral distraction helps to promote diffusion of oxygen, water and nutrients into the vertebral disc area, resulting to improved disc health by re-hydrating the degenerated disc. Retraction of a herniated nucleus pulposus (the soft gelatinous central portion of the intervertebral disc which resists compression) occurs with repeated pressure differential. The IDD therapy, therefore, decreases pressure on the discs, spinal nerves and vertebral joints through intermittent mobilizations while promoting retraction of herniated discs, disc healing, re-education of soft tissues, re-alignment of spinal structures and rehabilitation of damaged discs, which invariably reduces LBP. European Conformity (CE) as well as Food and Drug Administration (FDA)-cleared Class II fastest-growing medical devices, licenced to deliver IDD Therapy spinal decompression include the Accu-Spina and SDS (Safety Data Sheet) Spina. Clinicians can correctly and properly evaluate and adjust every single treatment on the IDD because every aspect of the therapy is recorded and adjustable [27].

This study therefore, was aimed at evaluating pain scores before and after using IDDT machine to achieve NSD amidst other conservative treatment (Low Level Laser Therapy (LLLT) and ultrasound therapy, spinal mobilisation, core strengthening and flexibility exercises and/or heat therapy) for adult patients with chronic mechanical LBP with or without radiculopathy. This study, therefore is pertinent in that chronic mechanical LBP is becoming prevalent in Africa and focus of management has only been on pain reduction using opioid pain medications which most often have drastic side effects. Non-surgical Spinal Decompression (NSD) delivered with IDDT machine may be cost-effective and a treatment of choice compared to spinal injection or surgery for most patients with low back pain [35]. Pain could be influenced by cultural and ethnical factors, therefore evaluating the outcome of LBP using routine physiotherapy management and IDDT amongst the Igbo tribe of Nigeria is deemed necessary.

\section{Method}

\section{Design \& sample}

We performed a retrospective pre-post study of a three and quarter year period (November, 2015 through March, 2019) on 141 consecutive adult patients with chronic LBP \pm radiculopathy who visited Astella physiotherapy clinics (which is located in Enugu; one of the states in South-Eastern Nigeria dominated by the Igbo tribe) and had routine physiotherapy (ultrasound and Low Level LASER therapy, spinal mobilisation, core strengthening and flexibility exercises, heat therapy) as well as NSD (Accu-Spina ${ }^{\circledR}$ with IDD Therapy ${ }^{\circledR}$ by North American Medical Corporation) of an average of 10 sessions over a 5 week-period. Data were collected from the Astella physiotherapy clinic records and IDD machine treatment records by the authors (EE, IN).

\section{Eligibility}

All adult patients who visited the clinic at some point within the three and quarter year period and presented with the following conditions were eligible: Bulging, protruded or degenerative discs with or without radiculopathy, spinal stenosis, sciatica, posterior facet joint dysfunction, chronic low back pain without improvement from prior conservative management. The above diagnoses were made by expert musculoskeletal physiotherapists (licensed physiotherapists with at least 5 years of clinical experience) following a broad and robust clinical evaluation based on the clinical assessment protocol established by the American College of Physicians and American Pain Society [36] and confirmed with Magnetic Resonance Imaging (MRI) reports where necessary. Patients who presented with muscular strain, spondylolysis, symptoms of cauda equina syndrome, diagnosed inflammatory disorder of the spine, spinal instability, spinal infection, previous lumbar surgery with hardware, spondylolisthesis greater than grade II, severe canal stenosis, presence of pacemaker, severe osteoporosis, evidence of lumbar compression fracture, spinal metastasis diagnosed upper motor neurone disorder and scoliosis were excluded. However, smokers and those with co-morbidities such as hypertension, diabetes, high cholesterol level were not excluded, though each patient was properly educated and treatment sessions spaced where necessary.

\section{Ethical consideration}

The study was conducted in accordance with Helsinki Declaration as revised in 2013 [37]. Every personally identifiable protected health information was excluded from this study in order to ensure the privacy and confidentiality of patient health information.

\section{Treatment protocol/procedure}

All the patients involved in this study had Non-surgical spinal decompression; however, it was preceded by the following: Low Level Laser Therapy (LLLT) and ultrasound therapy on the lumbar spine, spinal mobilisation (if not contraindicated), core strengthening and flexibility exercises and/or heat therapy. Initial treatment on the IDD started with a distraction force of half-body weight which was gradually increased from 5 to 20 pounds as the treatment progress. The most symptomatic spinal segment(s) were targeted first in relation to setting the angle of distraction.

Decompression was followed by cold therapy to reduce myogenic tension around the lumbar spinal area. Where indicated, Low Level Laser Therapy (LLLT) by 
Chattanooga group, Germany was applied for 5 to 10 minutes to the affected levels of the lumbar spine at the pre-programmed treatment settings $\{5 \times 100 \mathrm{~mW}(2.5$ $\mathrm{Hz}, 3.8$ joules $\left.\left./ \mathrm{cm}^{2}\right)\right\}$ if indicated. Low-level Laser Therapy is the minimum power density radiation (minimum red and infrared frequencies) irradiated on cells or tissues for reduction of pain and inflammation as well as activation of tissue regeneration $[38,39]$. Home exercise programs to increase core strength and flexibility were prescribed. These varied but were not limited to clamshell, pelvic tilt or shift, bridge, prone knee extension, bird dog, dead bug, prone leg raise, cat/camel, lumbar extension and rotation exercises with or without elastic band depending on patient's tolerance and capability. Some of these exercises target the local stabilizing muscles (transversus abdominis, lumbar multifidus, internal oblique muscle, and quadratus lumborum), providing accurate motor control and are therefore, primarily responsible in stabilizing the spine [40-43].

Other exercises involved the internal and external oblique muscles, erector spinae, quadratus lumborum, rectus abdominis, gluteal and hip muscle groups (also known as the global stabilizing muscles) which enable spinal control and are secondarily responsible for spinal stability. Strong core muscles help to protect the spine, maintain spinal stability and lower stress which impacts the lumbar vertebrae and intervertebral discs; therefore, the core muscles are also called "the natural brace" in individuals [41,43-46]. It is important to note that core muscle strengthening has been described as the cornerstone of conservatism in low back care [47]. More so, flexibility exercises were abdominals, quadratus lumborum, erector spinae, calf, piriformis, hamstrings, gluteal and hip flexors stretch as well as neural slides and myofascial release on the thoracolumbar fascia, quadratus lumborum, gluteal, piriformis and hamstring muscles and along sciatic nerve distribution on the affected leg(s) if indicated.

Patients were instructed to do 1 or 2 sets of 5 to 10 repetitions of each exercise once to twice daily as can be tolerated. The 11-point Numerical Pain Rating Scale (NPRS) was used to rate patients' pain prior and after intervention, with 10 as the "worst pain imaginable" and 0 as "no pain". On each patient's visit, starting and ending pain scores were recorded. The starting pain score at the beginning of the treatment plan and the ending pain score at the conclusion of the treatment regimen were recorded on each visit. In the event that the pa- tient failed to complete with the treatment, the ending pain at the date of the last visit was used.

\section{Outcome/outcome measures}

Pain intensity: This was assessed using the Numerical Pain Rating Scale (NPRS). NPRS is a well-established self-reported measure for assessing pain intensity. It is a very simple-to-use 11-point pain rating scale with 0 at the left, corresponding to "no pain", and 10 at the right side which means "worst possible pain" or "maximum pain". The scale provides valid and reliable pain scores [48]. In addition, NPRS has wide usability (can be used amongst individuals with low level of literacy) as well as applicability in several pain-related conditions [48-51].

Data analysis: Obtained data were cleaned and analysed with Statistical Package for Social Sciences (SPSS) version 15 by one of the authors (EE). Descriptive statistics of mean and standard deviation, frequency and percentage were used to summarize the demographic and clinical variables of the participants. Paired t-test was used to compare their mean pain intensities before and after treatment. Level of significance was set at $\alpha=0.05$.

\section{Results}

One hundred and forty-one patients (81 males, 60 females) with LBP who visited the clinic during the study period were analysed in this study. Most of the patients have had unsuccessful previous conservative management before reporting to the clinic. All patients had significant improvement except for 3 patients who reported an increased ending mean score and 2 patients who reported no change in average pain intensity score (pre-treatment and post treatment). A thorough clinical assessment was carried out on each patient. Magnetic Resonance Imaging (MRI) reports as well as broad and robust clinical assessments were used to confirm diagnosis. Diagnoses were made not just on MRI report but also, on broad and robust clinical assessments. One hundred and eleven cases were either suspected or confirmed discogenic pathology (such as disc bulge, disc herniation and degenerative disc disease); seven cases were facet syndrome while eighteen cases were combination of these two (discogenic pathology and facet syndrome). Furthermore, three cases had MRI-confirmed mild cord compression whereas only two cases were a combination of mild cord compression and disc dysfunction employing the classification of LBP by Jenkins [52] (Figure 1).

Table 1: Mean difference in pain intensity.

\begin{tabular}{|c|c|c|c|c|c|}
\hline \multirow[t]{2}{*}{ Pain Intensity } & \multirow[t]{2}{*}{ Mean } & \multirow{2}{*}{$\begin{array}{l}\text { Standard } \\
\text { deviation }\end{array}$} & \multicolumn{3}{|c|}{ Paired-samples T test } \\
\hline & & & df & $t$ & $p$ \\
\hline Starting pain intensity & 5.025 & 1.857 & \multirow[t]{2}{*}{134} & \multirow[t]{2}{*}{12.301} & \multirow[t]{2}{*}{$<0.001^{*}$} \\
\hline Ending pain intensity & 4.130 & 1.816 & & & \\
\hline
\end{tabular}

df: Degrees of freedom for each estimate of variance; $t$ : Size of the difference relative to the variation; $p$ : Significance level. 


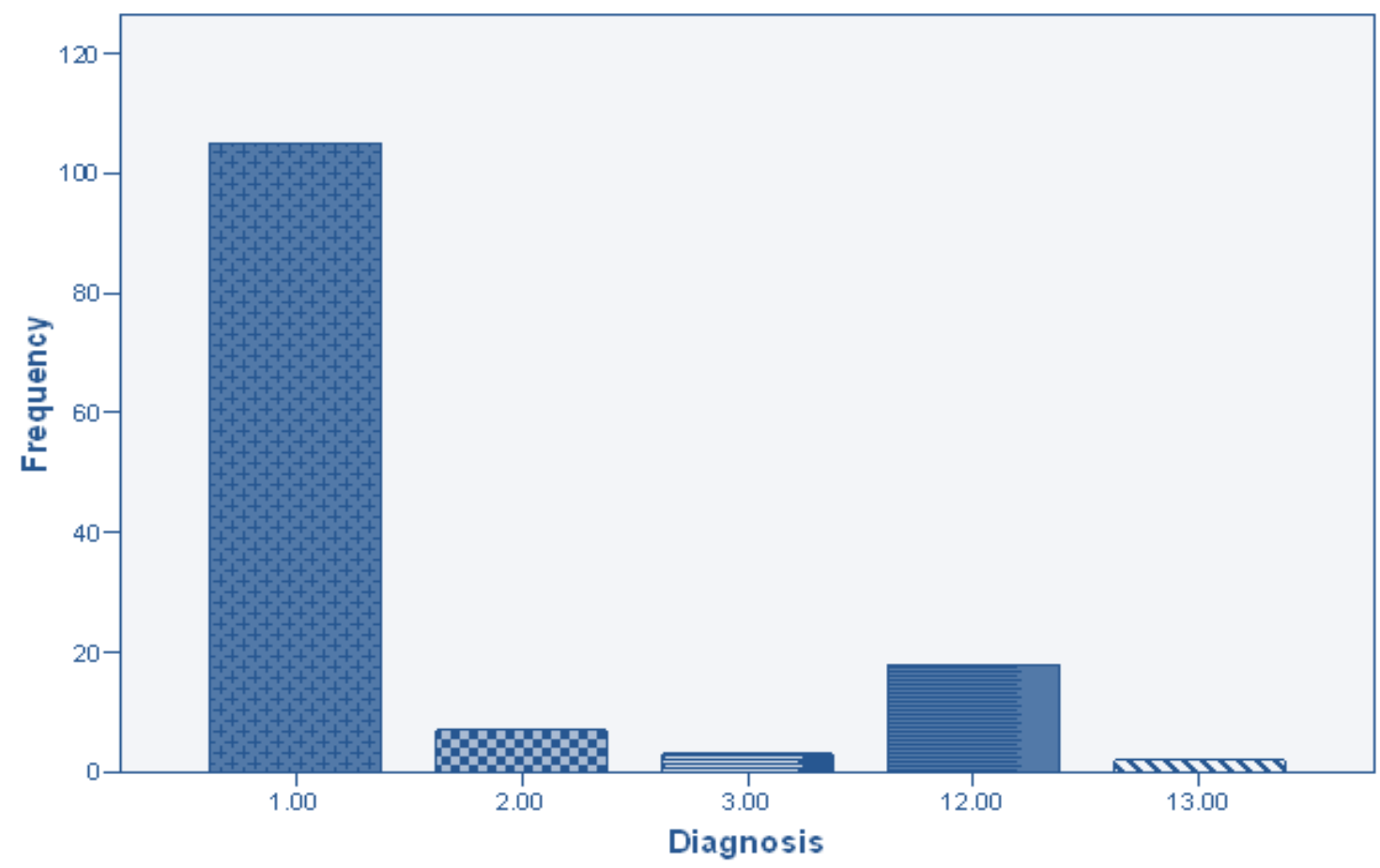

Key: Diagnosis-

1: Discogenic pathology (disc bulge or herniation and/or degenerative disc disease $\{$ spondylosis $\}$ );

2: Facet syndrome;

3: Cord compression;

12: Combination of discogenic pathology and facet syndrome;

13: Discogenic pathology with cord compression.

Figure 2: Diagnosis of the patients (majority confirmed with Magnetic Resonance Imaging \{MRI\}).

All the subjects were prescribed with core strengthening and flexibility exercises while hot pack and LLLT were applied pre-IDD treatment. Cold pack was applied after each IDD session to reduce or prevent muscular soreness even though this was not common among the patients. There were no serious adverse effects before, during and after treatment. The mean age of the patients was $54.73 \pm 13.82$ years ranging from 20 to 87 years with average weight of $192.39 \pm 36.10 \mathrm{lbs}(87.27$ $\pm 16.37 \mathrm{~kg}$ ). Number of therapy sessions ranged from 5 to 52 sessions. The average starting pain intensity score was $5.03 \pm 1.86$ whereas the mean ending pain intensity score was $4.13 \pm 1.82$ on an 11-point NPRS (Table 1 and Figure 2).

\section{Discussion}

This study examined, among other conservative treatments (Low Level Laser Therapy (LLLT) and ultrasound therapy, spinal mobilisation, core strengthening and flexibility exercises and/or heat therapy) in Nigeria, the outcome of LBP with or without radiculopathy for NSD delivered with IDDT machine. In this retrospective study, the patients were overwhelmingly male in their middle age. The findings of previous studies performed in Nigeria showed male predominance in line with this outcome, although there was no statistically significant gender gap $[7,53]$. These findings, however, contrast with the results of a previous systematic review, resulting in female preponderance or equivalent prevalence [9-12].

Majority of patients involved in this study were diagnosed with discogenic pathology. Consequently, this provides an example of the class of LBP prevalent in this population (i.e. LBP with or without radiculopathy, which is a more extreme form of mechanical LBP). This is not consistent with the finding of a previous study in Nigeria that reported spondylosis as the most common form of LBP [12]. In addition to this, a few of the patients in this study were clinically diagnosed with facet syndrome, which is also known as a basic mechanical type of LBP. Nevertheless, there may be some psychosocial overlay in patients studied in this research, but this cannot be determined as it is outside the scope of this research.

Exercises that target the core muscles (natural brace of human beings) have been reported to offer spinal protection, maintain spinal stability and decrease stress on the discs as well as the lumbar vertebrae $[45,46]$. Therefore, the resultant pain reduction in this study could also be attributed to the incorporation of these exercises in the treatment protocol. 


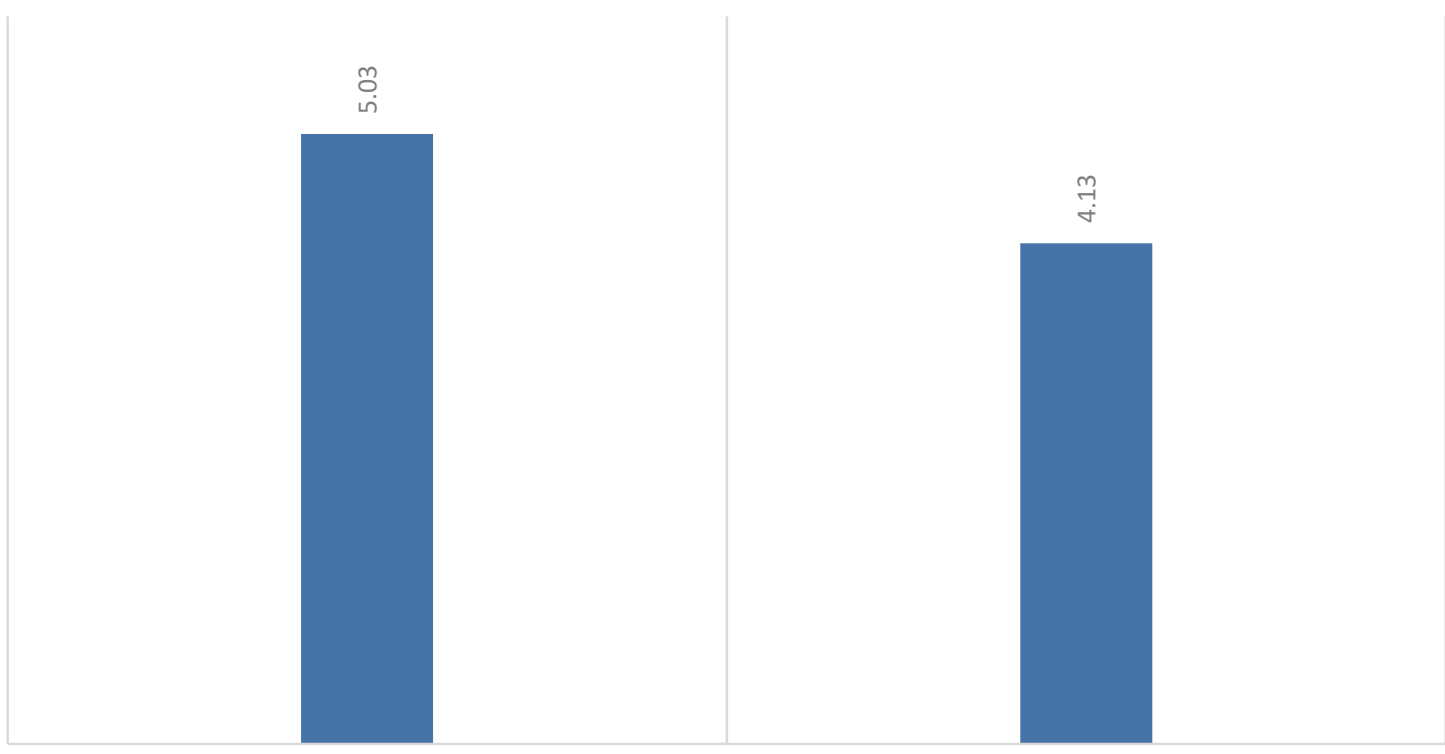

STARTING PAIN LEVEL

ENDING PAIN LEVEL

Figure 3: Low back (lumbar) pain prior and post intervention (including Non-surgical Spinal Decompression using IDDT device).

Despite its recommendation for cervical radiculopathy in the European 2017 National Clinical Guidelines, NSD is currently tagged as investigational due to insufficient evidence of its efficacy for various stages of LBP. Lack of comparative studies with established conservative treatments (standard medical care, exercise therapy and spinal manipulation) as well as cost have been the subject of controversy on NSD [54].

Nevertheless, the effectiveness of IDDT in the management of chronic LBP has been shown by findings from previous studies $[28,35,55,56]$. In a retrospective chart audit, it was confirmed that NSD uses DRX9000 and a treatment regimen (lumbar stretching, myofascial release, muscle relaxation and hot/cold application) to treat chronic LBP [57].

A preliminary study showed decompression relieved pain in patients with ruptured lumbar intervertebral disc pathology (86\%) as well as those with facet arthrosis (75\%) using the prototype of the Accu-Spina system [29]. However, these figures were based on very low sample sizes of 14 and 8 participants, respectively. Conversely, in a single-blind, randomized controlled study, two groups of low back pain patients treated with normal graded activity found that NSD was unsuccessful, with one of the groups receiving IDD Therapy ${ }^{\circledR}$ and the other group receiving sham therapy with a negligible amount of distractive force [55]. In the midst of this controversy, this present research shows a slightly lower mean patients ending pain severity score that were statistically significant despite these patients having reported no improvement with previous interventions (such as medication, routine physiotherapy, surgery). This is in line with previous findings in support of the efficacy of IDD therapy in conjunction with other conventional conservative treatment studies [28,35,55-57]. Although there was no control group used in this research, the authors would argue that it is difficult for a physical intervention to offer a persuasive placebo treatment. In addition, in a way, when the participants' pre and post intervention pain scores were compared, the patients served as their own "controls".

Our research was limited by certain factors. There was no definite set of routine physiotherapy for low back pain used in this study and as such, could have interfered with the results gotten. More so, exercise compliance was not assessed in this study as this could be a confounding factor. A major limitation was the absence of data on the use and the number of analgesic and anti-inflammatory drugs by the patients, since these drugs may have interfered with the quality and intensity of LBP. Due to the fact that only individuals with chronic (continuous pain lasting for duration of equal to or greater than 3 months) LBP were included in this research, the generalizability of these findings to a broader population with LBP may be limited. Therefore, a follow-up study with a control group is highly recommended. The recommended 20 intermittent sessions as recommended by the protocol, with a full 13 minutes of joint mobilization was strictly based on the manufacturer's experience. It remains uncertain if this is the optimal traction therapy protocol in the Accu-Spina system.

\section{Conclusion}

Mechanical LBP is more prevalent in middle-aged Nigerian men than in females. Combined with other pain 
relief physiotherapy modalities and exercises, non-surgical spinal decompression tends to provide pain relief in patients with LBP. There is a need to further study non-surgical spinal decompression for neck pain and long-term follow-up on low back pain with a control group.

\section{Acknowledgement}

The authors wish to thank the participants of this report.

\section{Conflicts of Interest}

There are no conflicts of interest.

\section{References}

1. Freburger JK, Holmes GM, Agans RP, Jackman AM, Darter JD, et al. (2009) The rising prevalence of chronic low back pain. Arch Intern Med 169: 251-258.

2. Hoy D, March L, Brooks P, Woolf A, Blyth F, et al. (2010) Measuring the global burden of low back pain. Best Pract Res Clin Rheumatol 24: 155-165.

3. Childs JD, Fritz JM, Flynn TW, Iragang J, Johnson KK, et al. (2004) A clinical predication rule to identify patients with low back pain most likely to benefit from spinal manipulation: A validation study. Ann Intern Med 141: 920-928.

4. Katz RT (2006) Impairment and disability rating in low back pain. Clin Occup Environ Med 5: 719-740.

5. National Institute of Health (2020) Low back pain fact sheet.

6. Omokhodion FO, Umar US, Ogunnowo BE (2000) Prevalence of low back pain among staff in a rural hospital in Nigeria. Occup Med (Lond) 50: 107-110.

7. Omokhodion FO (2002) Low back pain in a rural community in South West Nigeria. West Afr J Med 21: 87-90.

8. Enyichukwu O, Ogugua PC (2012) Epidemiology of low back pain in Enugu, Nigeria. Niger Journal of Orthopaedic Trauma 11: 28-35.

9. Meccui RD, Fassa AG, Faria NMX (2015) Prevalence of chronic low back pain: Systematic review. Rev Saude Publica 49: 1

10. Wang YXJ, Wang JQ, Kaplar Z (2016) Increased low back pain prevalence in females than in males after menopause age: Evidences based on synthetic literature review. Quant Imaging Med Surg 6: 199-206.

11. Awosan KJ, Yikawe SS, Oche OM, Oboirien M (2017) Prevalence, perception and correlates of low back pain among healthcare workers in tertiary health institutions in Sokoto, Nigeria. Ghana Med J 51: 164-174.

12. Edomwonyi EO, Ogbue IA (2017) Epidemiology of low back pain in a suburban Nigerian tertiary centre. Nigerian Journal of Surgical Sciences 27: 20-25.

13. Fabunmi AA, Aba SO, Odunaiya NA (2005) Prevalence of low back pain among peasant farmers in a rural community in South West Nigeria. Afr J Med Med Sci 34: 259-262.

14. Sanya AO, Ogwumike OO (2005) Low back pain prevalence amongst industrial workers in the private sector in Oyo State. Nigeria. Afr J Med Med Sci 34: 245-249.

15. Sikiru L, Shmailia H (2009) Prevalence and risk factors of low back pain among nurses in Africa: Nigerian and Ethopian specialised hospitals survey study. East Afr J Public Health 6: 22-25.
16. Sikiru L, Hanifa S (2010) Prevalence and risk factors of low back pain among nurses in a typical Nigeria hospital. Afr Health Sci 10: 26-30.

17. Ayanniyi O, Mbada CE, Muolokwu CA (2011) Prevalence and profile of back pain in Nigerian adolescents. Med Princ Pract 20: 368-373.

18. Hinmikaiye CD, Bamishaiye EI (2012) The incidence of low back pain among theatre nurses: A case study of University of Ilorin and Obafemi Awolowo University Teaching Hospital. International Journal of Nursing Science 2: 23-28.

19. Omoke NI, Amaraegbulam PI (2016) Low back pain as seen in orthopaedic clinics of a Nigerian Teaching Hospital. Niger J Clin Pract 19: 212-217.

20. Lopez AD, Mathers CD, Ezzati M, Jamison DT, Murray CJL (2006) Global and regional burden of disease and risk factors, 2001: Systematic analysis of population health data. Lancet 367: 1747-1757.

21. Hayden JA, van Tulder MW, Malmivaara AV, Koes BW (2005) Meta-analysis: Exercise therapy for nonspecific low back pain. Ann Intern Med 142: 765-775.

22. Machado LAC, de Souza MS, Ferreira PH, Ferreira ML (2006) The McKenzie method for low back pain: A systematic review of the literature with a meta-analysis approach. Spine (Phila Pa 1976) 31: E254-E262.

23. Gay R (2013) All about spinal decompression therapy. SPINE-health.

24. Stochkendahl MJ, Kjaer P, Hartvigsen J, Kongsted A, Aaboe J, et al. (2018) National clinical guidelines for non-surgical treatment of patients with recent onset low back pain or lumbar radiculopathy. Eur Spine J 27: 60-75.

25. Qaseem A, Wilt TJ, McLean RM, Forciea MA, Clinical Guidelines Committee of the American College of Physicians (2017) Noninvasive treatments for acute, subacute, and chronic low back pain: A clinical practice guideline from the American College of Physicians. Ann Intern Med 166: 514530.

26. National Institute for Health and Care Excellence (2016) Low back pain and sciatica in over 16s: Assessment and management.

27. Patnaik G (2018) Role of IDD therapy in the back and neck pain. J Med Stud Res 1: 002.

28. Shealey CN (2005) Intervertebral differential dynamics therapy. Practical Pain Management 5.

29. Choi J, Lee S, Hwangbo G (2015) Influences of spinal decompression therapy and general traction therapy on the pain, disability, and straight leg raising of patients with intervertebral disc herniation. J Phys Ther Sci 27: 481-483.

30. Kang JI, Jeong DK, Choi H (2016) Effect of spinal decompression on the lumbar muscle activity and disk height in patients with herniated intervertebral disk. J Phys Ther Sci 28: 3125-3130.

31. Demirel A, Yorubulut M, Ergun N (2017) Regression of lumbar disc herniation by physiotherapy. Does non-surgical spinal decompression therapy make difference? Double-blind randomized controlled trial. J Back Musculoskelet Rehabil 30: 1015-1022.

32. Shaw WS, Campbell P, Nelson CC, Main CJ, Linton SJ (2013) Effects of workplace, family and cultural influences on low back pain: What opportunities exist to address social factors in general consultations? Best Pract Res Clin Rheumatol 27: 637-648. 
33. Tavafian SS, Gregory D, Montazeri A (2008) The experience of low back pain in Iranian women: A focus group study. Health Care Women Int 29: 339-348.

34. Shipton EA (2013) The pain experience and sociocultural factors. N Z Med J 126: 7-9.

35. Henry L (2017) Non-surgical spinal decompression an effective physiotherapy modality for neck and back pain. $J$ Nov Physiother Phys Rehabil 4: 62-65.

36. Horsley L (2008) ACP guidelines for the diagnosis and treatment of low back pain. Am Fam Physician 77: 1607-1610.

37. Arie S (2013) Revision of Helsinki declaration aims to prevent exploitation of study participants. BMJ 347: 6401.

38. Omar MTA, Shaheen AAM, Zafar H (2012) A systematic review of the effect of low-level laser therapy in the management of breast cancer-related lymphedema. Support Care Cancer 20: 2977-2984.

39. Zecha JAEM, Raber-Durlacher JE, Nair RG, Epstein JB, Elad S, et al. (2016) Low-level laser therapy/photobiomodulation in the management of side effects of chemoradiation therapy in head and neck cancer: Part 2: Proposed applications and treatment protocols. Support Care Cancer 24: 2793-2805.

40. Fairbank JC, Couper J, Davies JB, O'Brien JP (1980) The Oswestry low back pain disability questionnaire. Physiotherapy $66: 271-273$.

41. Pfirrmann CW, Metzdorf A, Zanetti M, Hodler J, Boos N (2001) Magnetic resonance classification of lumbar intervertebral disc degeneration. Spine (Phila Pa 1976) 26: 1873-1878.

42. Anjana RM, Pradeepa R, Das AK, Deepa M, Bhansali A, et al. (2014) Physical activity and inactivity patterns in India - results from the ICMR-INDIAB study (Phase-1) [ICMR-INDIAB-5]. Int J Behav Nutr Phys Act 11: 26.

43. Panjabi MM (1992) The stabilizing system of the spine. Part II. Neutral zone and instability hypothesis. J Spinal Disord 5: 390-396.

44. Parker SL, Mendenhall SK, Shau D, Adogwa O, Cheng JS, et al. (2012) Determination of minimum clinically important difference in pain, disability, and quality of life after extension of fusion for adjacent-segment disease. J Neurosurg Spine 16: 61-67.

45. Brumitt J, Matheson JW, Meira EP (2013) Core stabilization exercise prescription, part I: Current concepts in assessment and intervention. Sports Health 5: 504-509.
46. Cosio-Lima LM, Reynolds KL, Winter C, Paolone V, Jones MT (2003) Effects of physioball and conventional floor exercises on early phase adaptations in back and abdominal core stability and balance in women. J Strength Cond Res 17: 721-725.

47. Shiju MA, Anish TS, Asha S, Arun MS (2019) The effectiveness of a simplified core stabilization program (TRICCS-Trivandrum Community-based Core Stabilisation) for community-based intervention in chronic non-specific low back pain. J Orthop Surg Res 14: 86.

48. Castarlenas E, Jensen MP, von Baeyer CL, Miro J (2017) Psychometric properties of the numerical rating scale to assess self-reported pain intensity in children and adolescents: A systematic review. Clin J Pain 33: 376-383.

49. Hjermstad MJ, Fayers PM, Haugen DF, Caraceni A, Hanks GW, et al. (2011) Studies comparing numerical rating scales, verbal rating scales, and visual analogue scales for assessment of pain intensity in adults: A systematic literature review. J Pain Symptom Manag 41: 1073-1093.

50. Bourdel N, Alves J, Pickering G, Ramilo I, Roman H, et al. (2015) Systematic review of endometriosis pain assessment: How to choose a scale? Hum Reprod Update 21: 136-152.

51. Castarlenas E, de la Vega R, Jensen MP, Miro J (2016) Self-report measures of hand pain intensity: Current evidence and recommendations. Hand Clin 32: 11-19.

52. Jenkins H (2002) Classification of low back pain. Australasian Chiropractic \& Osteopathy 10: 91.

53. Okpala OF (2017) Radiographic lumbar spondylosis: Gender and age group prevalence in Nigeria. Annals of Tropical Medicine and Public Health 10: 1199-1204.

54. Daniel DM (2007) Non-surgical decompression therapy: Does the scientific literature support efficacy claims made in the advertising media? Chiropr Osteopat 15: 7.

55. Schimmel JJP, de Kleuver M, Horsting PP, Spruit M, Jacobs $\mathrm{WCH}$, et al. (2009) No effect of traction in patients with low back pain: A single centre, single blind, randomized controlled trial of Intervertebral Differential Dynamics Therapy. Eur Spine J 18: 1843-1850.

56. SchaufeleMK, Newsome N (2011) Intervertebral Differential Dynamics (IDD). Phys Med Rehab Kuror 21: 34-40.

57. Macario A, Richmond C, Auster M, Pergolizzi JV (2008) Treatment of 94 outpatients with chronic discogenic low back pain with the DRX9000: A retrospective chart review. Pain Pract 8: 11-17. 